\title{
An optimized design method of three-point support for precision horizontal machining center with T- shape bed
}

\section{Zixin Lin}

Tianjin University

Wenjie Tian ( $\nabla$ wenjietian@tju.edu.cn )

Tianjin University https://orcid.org/0000-0002-7853-8463

Dawei Zhang

Tianjin University

Weiguo Gao

Tianjin University

\section{Lina Wang}

Tianjin University

\section{Research Article}

Keywords: Precision horizontal machining center, T-shape bed, Three-point support, Optimized design

Posted Date: September 15th, 2021

DOl: https://doi.org/10.21203/rs.3.rs-893966/v1

License: (9) This work is licensed under a Creative Commons Attribution 4.0 International License. Read Full License 


\title{
An optimized design method of three-point support for precision horizontal machining center with T-shape bed
}

\author{
Zixin Lin ${ }^{\mathrm{a}}$, Wenjie Tian ${ }^{\mathrm{b}}$, Dawei Zhang ${ }^{\mathrm{a}}$, Weiguo Gao ${ }^{\mathrm{a}}$, Lina Wang ${ }^{\mathrm{a}}$ \\ ${ }^{a}$ Key Laboratory of Mechanism Theory and Equipment Design of Ministry of Education, Tianjin \\ University, Tianjin, China \\ ${ }^{\mathrm{b}}$ School of Marine Science and Technology, Tianjin University, Tianjin, China \\ ${ }^{*}$ Corresponding author:
}

Tel./fax: +86 15822450489. E-mail addresses: wenjietian@tju.edu.cn(W. Tian)

\begin{abstract}
The support point layout of the machine tool has an important influence on the working performance of the machine tool, when the material, manufacturing process and internal structure of machine bed are determined. In order to ensure that the precision machine tool has good leveling performance, stability and anti-interference, this paper presents an optimized design method of threepoint support for T-shape bed of precision horizontal machining center. This article first establishes the statics model of the T-shape bed and analyzes grillage beam model used to characterize the main static deformation trend of the bed based on the singular function method. After verifying the rationality of the model through simulation, the optimized three-point support position can be obtained. Then this paper measured the deformation of the upper surface of a simple bed due to gravity. The deviation between the experimental results and the simulation results is less than $20 \%$, which verifies the reliability of the simulation and theoretical results. Based on the ISIGHT multi-disciplinary optimization platform, this paper completes the multi-objective optimization of the support point layout of the bed, and the optimization results prove the accuracy of the theoretical model. This paper takes the bed of $\mathrm{M} 800 \mathrm{H}$ precision horizontal machining center as an example to illustrate the application process of the proposed method. Finally, this paper compares the optimization effect of the static characteristics of the bed and the whole machine. The maximum deformation of the bed has reduced by $27.1 \%$. In the whole machine status, the deformation of the spindle end has reduced by $50.8 \%$, and the maximum deformation of the workpiece end have reduced by $50.0 \%$.
\end{abstract}

Key words: Precision horizontal machining center; T-shape bed; Three-point support; Optimized design

\section{Introduction}

With the rapid development of science and technology, the CNC machine tool industry is developing by leaps and bounds in the direction of high precision, diversified functions, and high speed. As the processing equipment used in the manufacturing industry, CNC machine tools are widely used in the manufacture of key parts and components in aerospace, shipbuilding, and military industries. Therefore, improving the machining accuracy of CNC machine tools is of great significance to improving the level of equipment manufacturing. ${ }^{1}$

The main factors affecting the machining accuracy of CNC machine tools include the static and dynamic characteristics, vibration resistance and thermal deformation resistance. ${ }^{2}$ Bed is an important basic part of the machine tool, and its static and dynamic performance has a great influence on the machining accuracy of the machine tool. The factors that affect the static and dynamic performance of the bed mainly include the topology, material properties, manufacturing processes, and support methods. ${ }^{3}$ Support point layout has an important influence on the working performance of the machine tool, when the material properties, manufacturing process, and internal topological structure of the machine bed are determined.

Luo WP proposed three support structure arrangements for five-axis CNC machine tools, and studied the impact of the three support structures on the static and dynamic performance of the machine through simulation. He proved that the support structure of the machine tool has a great influence on the machining accuracy of the whole machine. Improving the support structure of the machine tool can effectively improve the machining accuracy of the machine tool. ${ }^{4}$ In order to improve the performance of a horizontal machining center with three-point support as the main support, Wang QL provided three support layout schemes for adding auxiliary support to the relatively weak part of the bed. He analyzed the influence of auxiliary support on the static and dynamic characteristics of the bed through simulation, and proposed that a reasonable addition of auxiliary support can effectively increase the rigidity and stability of the bed. ${ }^{5}$ Focus of scholars on the support technology currently is not limited to specific support methods. Their focus is mainly on the simulation and testing of the contact stiffness of the support area. Szwengier G. and Godunski T used the test results of the support area of the machine bed to modify 
the support stiffness model and verify the accuracy of the support stiffness model. ${ }^{6}$ Daisuke $\mathrm{K}$ and Takahiro I believe that the rigidity between the machine bed and the supporting surface consists of two parts: contact rigidity and solid rigidity. They established a three-dimensional stiffness model, and fitted the contact stiffness between the metal and the ground by static loading test deformation. On this basis, they applied the stiffness parameter to the modal analysis of a certain machine tool, and verified the accuracy of the stiffness model for predicting the support stiffness of the machine bed. ${ }^{7}$ Zhang $\mathrm{H}$ et al. proposed that the foot joint interface of the bed can be equivalent to a three-way spring damping system. They identified the equivalent stiffness and damping parameters of the foot joint interface through modal tests, and finally verified the parameter identification results through finite element simulation. ${ }^{8}$

The optimization design for the static and dynamic performance of the bed is also mainly for the optimization design of the bed structure, and there are relatively few studies on the optimal design of the layout of the support points of the bed. Researchers have proposed many optimization design methods and design theories, such as BP neural network ${ }^{9}$, sensitivity method ${ }^{10}$, genetic algorithm ${ }^{11}$, response surface method ${ }^{12}$ and multi-objective optimization. ${ }^{13-15}$

The support feet of the traditional bed are multiple with many contact points, which is not conducive to the leveling of the bed. It will affect the vibration characteristics of the machine tool and decrease the processing quality and service life of the machine tool. The three-point support is to use three anchor bolts to connect the machine bed and the foundation, which realizes the support of the whole machine. Due to the principle of three points to determine one side, the three-point support method is convenient for the leveling of the machine tool. This support method not only enables the bed to have less internal stress, higher stability and better accuracy retention, but also saves installation costs and shortens the installation cycle. ${ }^{16}$

At present, the layout design method for the three-point support on the bed is still limited to the comparative method. The designer repeatedly modified the position of the three-point support and arranged a limited combination of parameters for numerical simulation analysis and calculation based on the design experience. They finally selected the best performance from the limited combination of parameters. ${ }^{16}$ This method is difficult to ensure that the selected parameter combination is optimal, and it takes a lot of time to select the parameter combination and perform numerical simulation analysis and calculation. Therefore, this paper presents an optimized design method of three-point support for T-shape bed of precision horizontal machining center. This method simplifies the T-shape bed into a grillage beam model that can characterize the static deformation trend of the bed, and cooperates with the multiobjective optimization method of ISIGHT to obtain the optimal support point layout. This method can used to guide the support layout design for T-shape bed of precision horizontal machining center, and used to complete the optimization design according to different optimization goals, and improve the efficiency of optimization. It will improve the efficiency of optimization and the accuracy of optimization results.

Section 2 establishes a static model of the T-shape bed. Then the deformation trend of the grillage beam obtained from the static model based on the singular function method can analyzed. This section takes the $\mathrm{M} 800 \mathrm{H}$ bed as an example and compares the model analysis results and ANSYS finite element analysis results to verify the rationality of the model. A set of optimal three-point support positions can be obtained from this model. Section 3 introduces the verification experiment with a simple bed, which proves that the ANSYS simulation results of the bed surface deformation are reliable. Section 4 uses the $\mathrm{M} 800 \mathrm{H}$ bed as the research object to build a multidisciplinary optimization process based on ISIGHT, and obtains the Pareto solution set. This result proves the accuracy of optimal three-point support positions in the section 2. Sections 5 compares the optimization effect of the static characteristics of the bed and the whole machine. The comparison results show the effectiveness of the optimization method. Finally, Section 6 is the conclusion of this paper.

\section{Statics modeling of three-point support for T-shaped bed}

\subsection{Static modeling of the T-shaped bed}

As shown in Fig. 1, in the machine tool coordinate system, the deformation of the bed affected by gravity is mainly manifested as the deformation in the Y-direction. Therefore, the deformation of the bed can be divided into the deformation of the Y-direction in the X-direction straight line and the Z-direction straight line. For the bed with a Tic-shaped rib structure inside, as shown in Fig. 2, the static deformation trend can be characterized by the static deformation trend of the X-direction ribs and Z-direction ribs inside. 


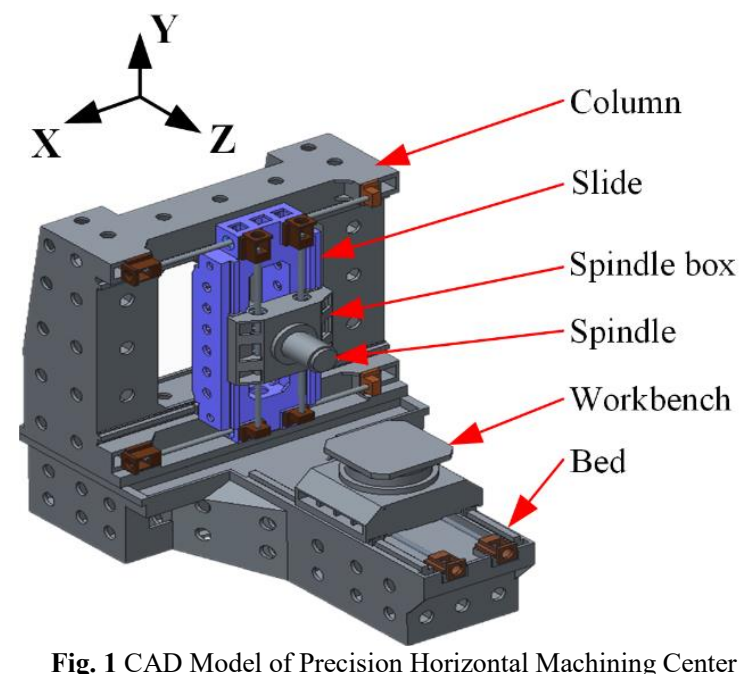

The center point of the contact surface between the support foot of the machine tool and the foundation called the support point. The X-direction ribs and Z-direction ribs in the bed that overlap the supporting point in the bed can be constructed, and these ribs called the main ribs. The thickness of the main rib is the same as the original rib in the bed. The gravity of the bed acts on each supporting point, which can be regarded as acting on each main ribs. Therefore, the bed can be simplified as a grillage beam model composed of support points and main ribs, as shown in Fig. 3. Then the gravity of the bed can equivalently act on the grillage beam model.

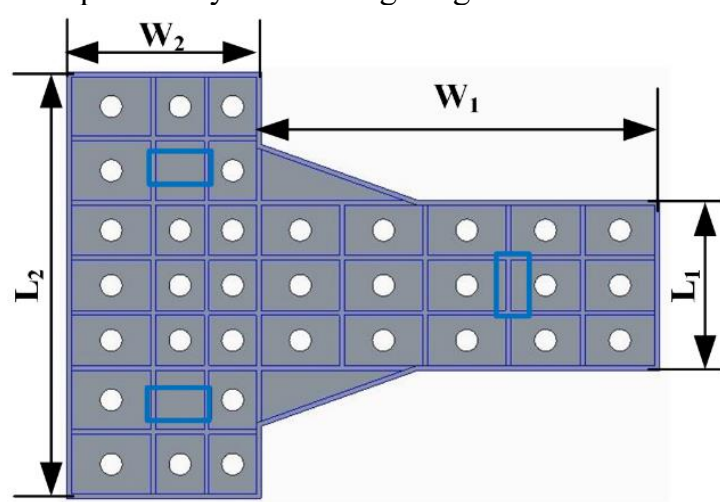

Fig. 2 The ribs layout of the T-shaped bed

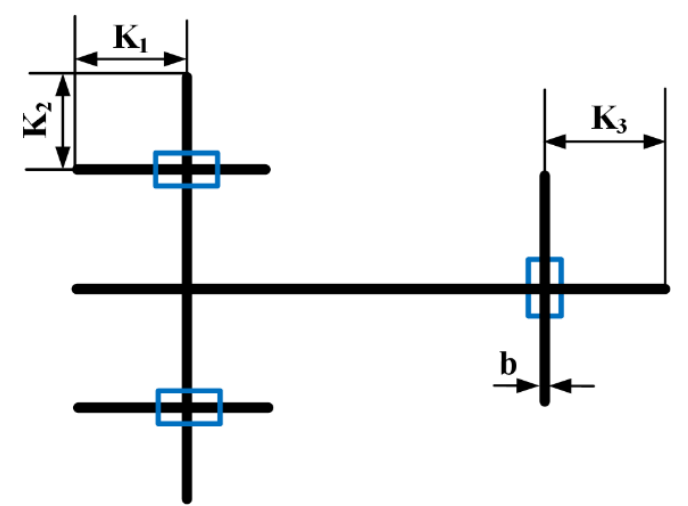

Fig. 3 The simplified grillage beam model of T-section bed

When the cross-sectional dimensions of all beams in the grillage beam model are equal, the linear uniform load $q_{C}$ on the grillage beam due to the gravity of the bed is:

$$
q_{C}=\frac{G b}{S}
$$

Where $\mathrm{G}$ is the gravity of the bed, $\mathrm{b}$ is the thickness of the beam and $\mathrm{S}$ is the top area of the grillage beam model.

When the cross-sectional dimensions of all beams in the grillage beam model are not equal, the relationship between the linear load distribution function on each beam and the gravity of the bed is:

$$
G=\int_{0}^{L_{1}} q_{1}(x) d x+\int_{0}^{L_{2}} q_{2}(x) d x+\mathrm{L} \mathrm{L}+\int_{0}^{L_{n}} q_{n}(x) d x
$$

Where $L_{i}(i=1,2,3 \ldots n)$ are the length of each beam in the grillage beam model and $q_{i}(x)(i=1,2,3 \ldots n)$ are the linear load distribution function on the beam.

The load value of the linear load distribution function $q_{i}(x)$ distributed on the beam at different sections meets the following conditions:

$$
\frac{q\left(x_{1}\right)}{q\left(x_{i}\right)}=\frac{h_{1}}{h_{i}}
$$


Where $x_{i}(i=1,2,3 \ldots n)$ are the length coordinates of different sections of the beam, $h_{i}(i=1,2,3 \ldots n)$ are the height at different sections of the beam.

According to Equations (2) and (3), the load distribution function of the gravity of the bed distributed on each beam can be obtained.

\subsection{The static deformation trend of grillage beam}

The static deformation trend of the beam can be represented by the deflection curve of the beam, and the deflection curve diagram of the beam can be drawn according to the deflection curve equation of the beam.

In material mechanics, there are two main methods for solving the deflection curve equation of a beam: the integral method ${ }^{17}$ and the superposition method ${ }^{18}$. These two methods are very troublesome for solving statically indeterminate beams with multiple support points under complex load conditions, and they may not be able to solve the deflection curve equation of the beam. Therefore, this paper uses the singular function method to solve the beam deflection curve equation. ${ }^{19}$

The definition of singular function is ${ }^{19}$ :

$$
f_{n}(x)=<x-a>^{n}= \begin{cases}(x-a)^{n}, & x \geq a, n \geq 0 \\ 0, & x<a, n \geq 0 \\ \infty, & x=a, n<0 \\ 0, & x \neq a, n<0\end{cases}
$$

Where brackets $<>$ are generally called Macauley brackets, and $a$ is a constant.

The calculus operation rules for singular functions are:

$$
\begin{aligned}
& \left.\frac{d}{d x}<x-a\right\rangle^{n}= \begin{cases}<x-a\rangle^{n-1}, \\
n<x-a\rangle^{n-1},\end{cases} \\
& \int_{-\infty}^{x}<x-a>^{n}= \begin{cases}<x-a>^{n+1}, & n>0 \\
\frac{1}{n+1}<x-a>^{n+1}, & n>0\end{cases}
\end{aligned}
$$

The singular function expressions of common loads of beams are shown in Table 1. Herein, $a$ is the starting point coordinate of the load; $b$ is the acting length of the distributed load; $L$ is the length of the beam, $M$ is the moment of couple; $F$ is the concentrated force; $q$ is the linear uniform load; $q_{0}$ is the load value at the right end of the linear load distribution range; $q_{(t)}$ is the load distribution function of the linear load. $W_{M}(x), W_{F}(x), W_{F}(x), W_{q f}(x)$ are the sum of the singular function expressions of all the moment of couple, the concentrated force, the linear uniform load and distributed load on beam, respectively.

Table 1 Singular function expressions of common loads on beams

\begin{tabular}{cccc}
\hline Load type & Singular function expressions & Graphical representation & $W_{M}(\mathrm{x})=M<x-a>^{-2}$ \\
The moment of \\
couple
\end{tabular}




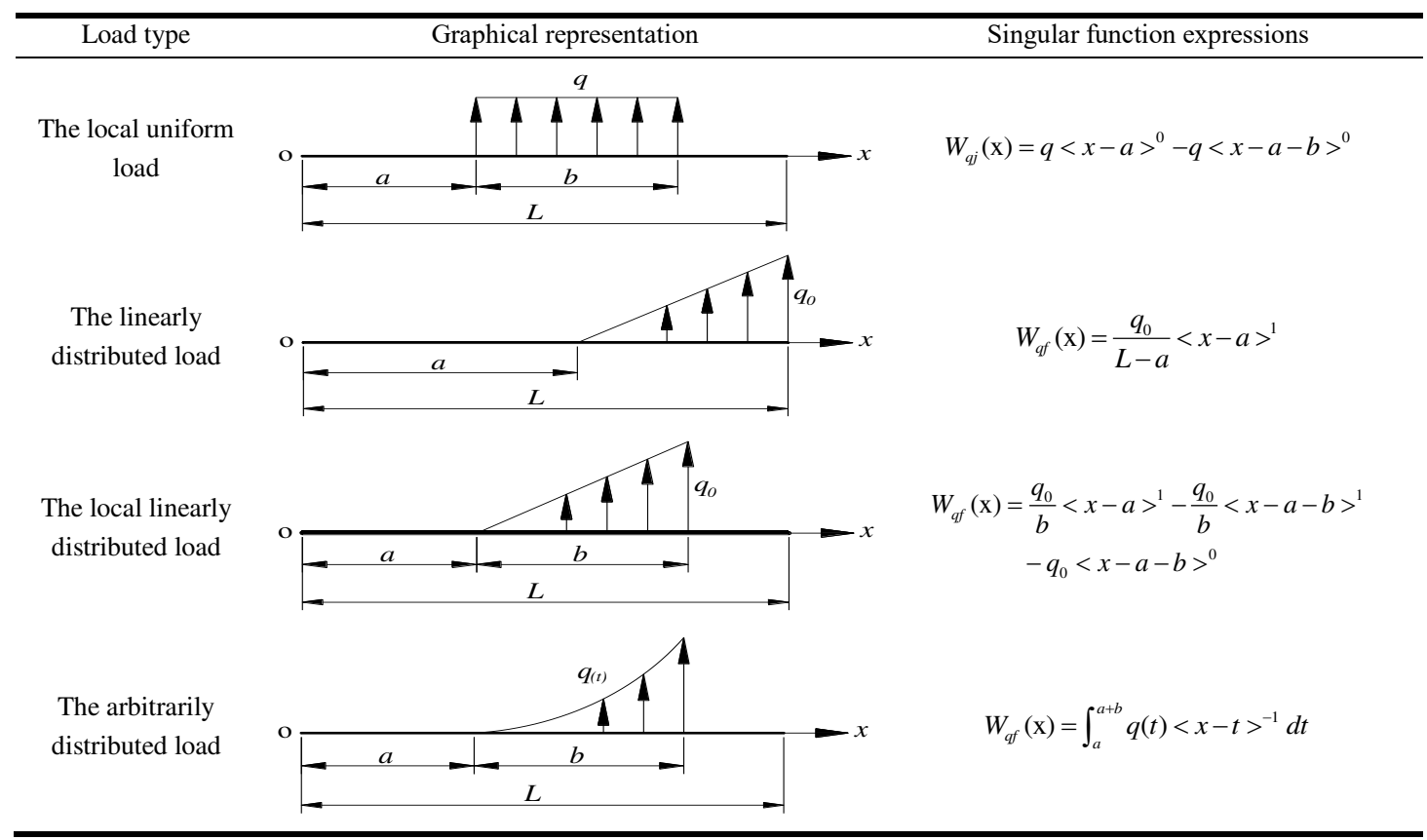

The beams in the simplified grillage-beam model of the bed are usually of equal cross-section. We can add the load on the beam according to the above method, remove the support of the beam and add the reaction force at the support point. A load concentration function $W(x)$ including all loads on the beam can expressed as:

$$
W(x)=W_{M}(x)+W_{F}(x)+W_{q j}(x)+W_{q f}(x)
$$

The shear force expression $Q(x)$ of the beam can be obtained by integrating the load concentration function once.

$$
Q(x)=\int_{0}^{L} W(x) d x
$$

The bending moment expression $M(x)$ of the beam can be obtained by integrating the shear force expression.

$$
M(x)=\int_{0}^{L} Q(x) d x
$$

According to the static balance condition of the beam, the shear force and the static moment at the end of the beam are 0 , that is:

$$
\begin{aligned}
& Q(L)=0 \\
& M(L)=0
\end{aligned}
$$

In material mechanics, the differential equation of beam deflection curve is:

$$
\operatorname{EIy}^{\prime \prime}(x)=M(x)
$$

Where, $y(x)$ is the deflection expression of the beam, $E$ is the elastic modulus of the beam material, and $I$ is the inertia moment of the beam section.

The angle expression $\theta(x)$ and the deflection expression $y(x)$ of the beam can be obtained by integrating the deflection curve differential equation.

$$
\begin{aligned}
& E I \theta(x)=\int M(x) \mathrm{d} x+C \\
& E I y(x)=\int\left(\int M(x) \mathrm{d} x+C\right) \mathrm{d} x+D
\end{aligned}
$$

Where $C$ and $D$ are both integral constants.

The boundary conditions are:

When the supporting point of the beam is a hinged support, the deflection at the supporting point is zero. When the supporting point of the beam is a fixed support, the rotation angle and deflection at the supporting point are both zero.

We can calculate the integral constant through simultaneous equations of Equations (9), (10), (13) and boundary conditions. Then the boundary conditions can be substituted into Equation (12) and beam 
deflection curve equation can obtained.

In order to obtain the static deformation trend of the grillage beam model, the grillage-beam model can be decomposed into X-direction beams and Z-direction beams for analysis. Each foot support point can be simplified as a fixed support, and the rest of the support points can be simplified as a hinged support.

\subsection{Example}

The CAD model of the bed of the M800H precision horizontal machining center is shown in Fig. 4. The bed is a monolithic casting structure with a Tic-shaped rib structure inside. There are three supporting horns at the bottom of the bed.

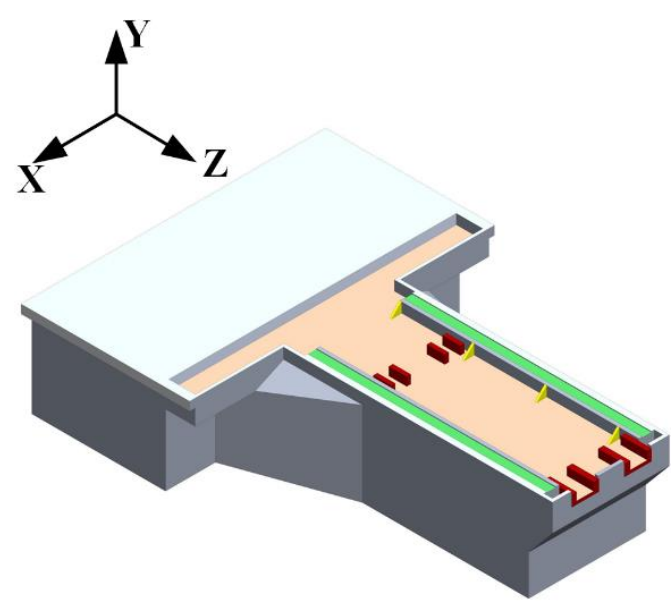

Fig. 4 CAD Model of the Bed of Horizontal Machining Center

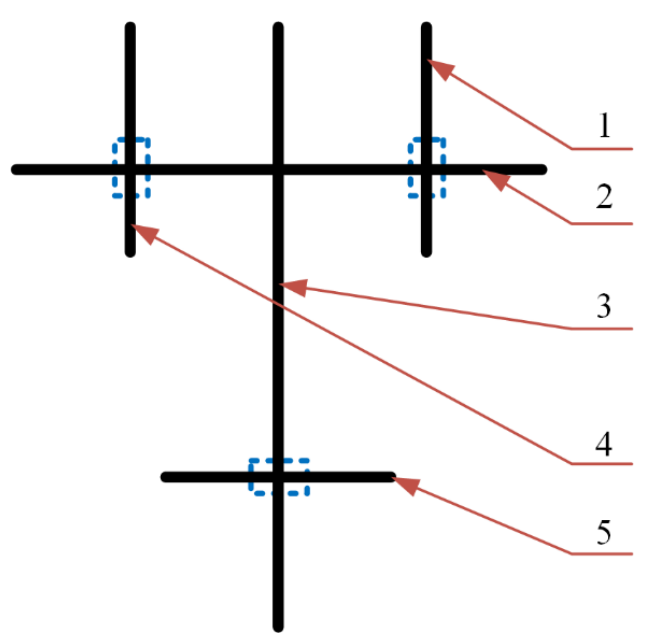

Fig. 5 Simplified grillage beam model of horizontal machining center bed

The width of each rib in the bed is equal and the height difference of the ribs is small. In order to facilitate the analysis of the static deformation trend of the bed, each rib can be regarded as a constant cross-section rib. There are 5 beams in the simplified grillage beam model of the bed, which are represented by serial numbers 1 to 5 , as shown in Fig. 5. The parameters of the grillage beam model are shown in Table 2. The initial foot position of the bed is designed by experience, and the position parameters are $K_{l}=560 \mathrm{~mm}, K_{2}=540 \mathrm{~mm}, K_{3}=680 \mathrm{~mm}$.

Table 2 The parameters of the grillage beam model

\begin{tabular}{cccl}
\hline Parameter & Value & Parameter & Value \\
\hline The length of the front bed $\mathrm{L}_{1}(\mathrm{~mm})$ & 2535 & The length of the back bed $\mathrm{L}_{2}(\mathrm{~mm})$ & 2714 \\
The width of the front bed $\mathrm{W}_{1}(\mathrm{~mm})$ & 1080 & The width of the back bed $\mathrm{W}_{2}(\mathrm{~mm})$ & 1235 \\
Beam thickness $\mathrm{b}(\mathrm{mm})$ & 30 & Beam height $\mathrm{H}(\mathrm{mm})$ & 880 \\
The weight of the bed $m_{c}(\mathrm{~kg})$ & 9060.76 & Poisson's ratio $\mu$ & 0.3 \\
Elastic modulus $E(\mathrm{MPa})$ & $1.73 \mathrm{e}^{5}$ & Acceleration of gravity $g(\mathrm{~N} / \mathrm{kg})$ & 9.8 \\
\hline
\end{tabular}

The deflection expressions and related conditional expressions of each beam can be obtained by the singular function method. Simultaneous equations are calculated by MATLAB software. Then the deflection curve graph of each beam can be obtained, as shown in the blue curve in Fig. 6.

The point on the surface of the bed that overlaps the grillage beam model can indicate the actual static deformation trend of the bed. We performed static analysis on the machine tool model in ANSYS finite element analysis software and extracted the deformation of the corresponding point of the grillage beam model in the Y-direction. The deflection curve graphs of each beam are shown in the red curve in Fig. 6.

$\# 1$ beam and \#4 beam have the same length and the same load conditions, so their deformation curves are the same, as shown in Fig. 6(a), 6(b) and Fig. 6(g), 6(h). We regard the support of the beam as a rigid support and ignore the deformation of the support. The beam deformation curves obtained by the two analysis methods are different at the support point, as shown in the Fig.6.

It can be seen from the above figure that the trend of the beam deformation curves obtained by these two analysis methods is almost the same. So, it is reasonable to simplify the bed as a grillage beam model to analyze the static deformation trend of the bed. 


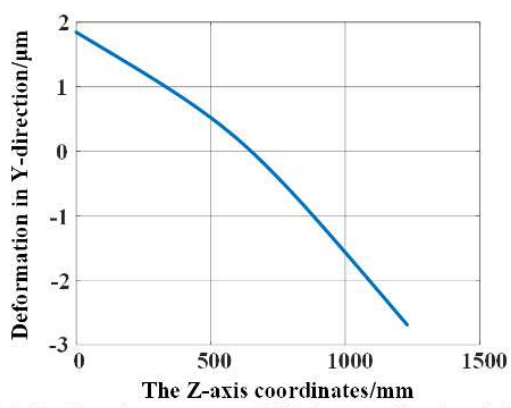

(a) Deflection curve of $\# 1$ beam obtained by static deformation trend analysis

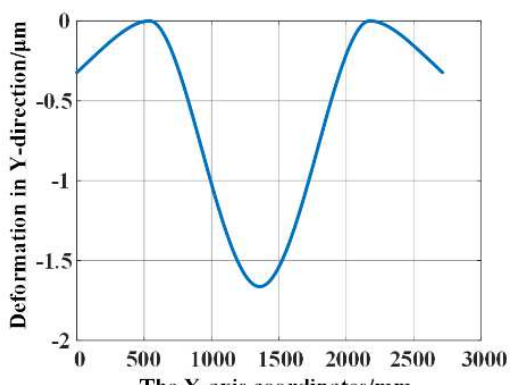

(c) Deflection curve of $\# 2$ beam obtained by static deformation trend analysis

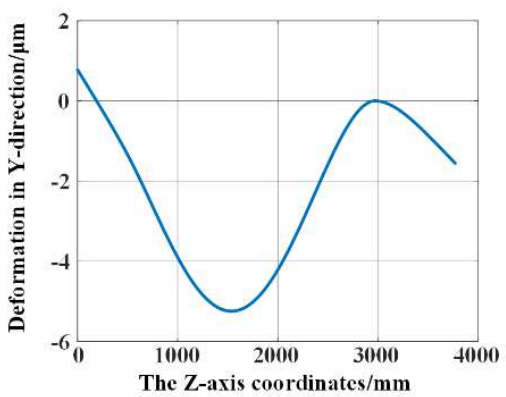

(e) Deflection curve of \#3 beam obtained by static deformation trend analysis

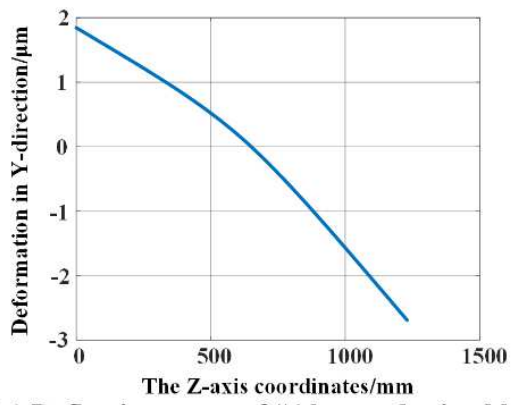

(g) Deflection curve of $\# 4$ beam obtained by static deformation trend analysis

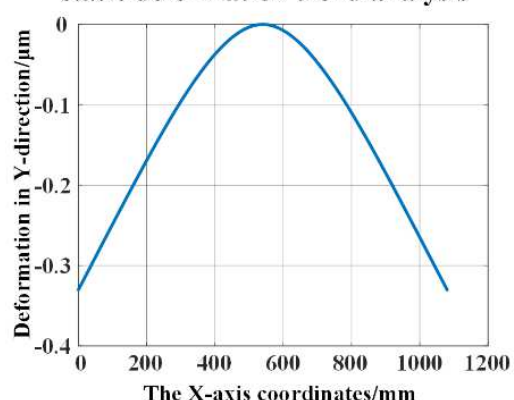

(i) Deflection curve of $\# 5$ beam obtained by static deformation trend analysis

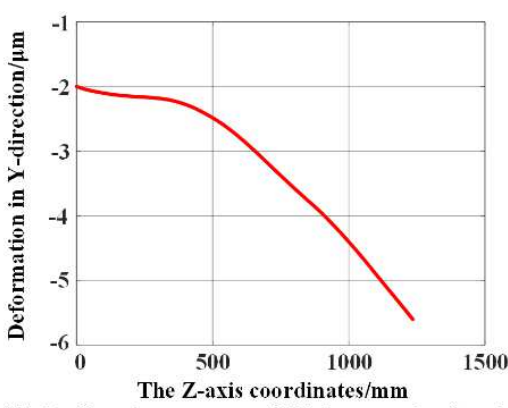

(b) Deflection curve of \#1 beam obtained by ANSYS simulation

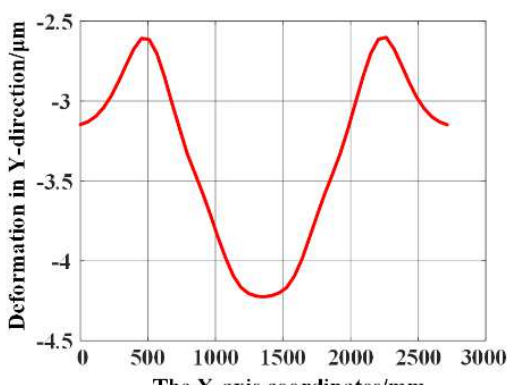

(d) Deflection curve of $\# 2$ beam obtained by ANSYS simulation

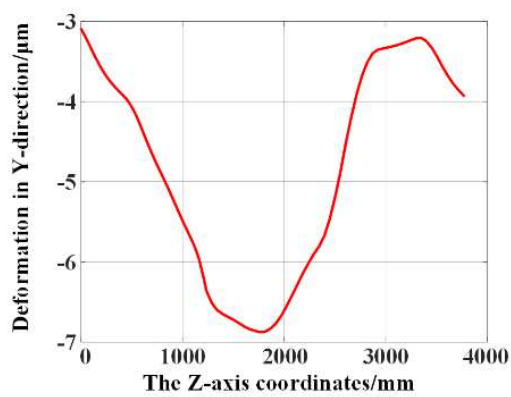

(f) Deflection curve of \#3 beam obtained by ANSYS simulation

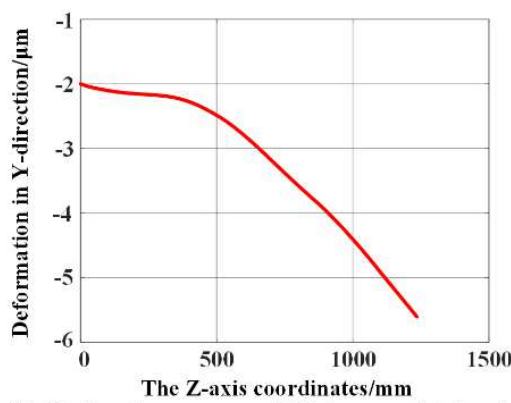

(h) Deflection curve of $\# 4$ beam obtained by ANSYS simulation

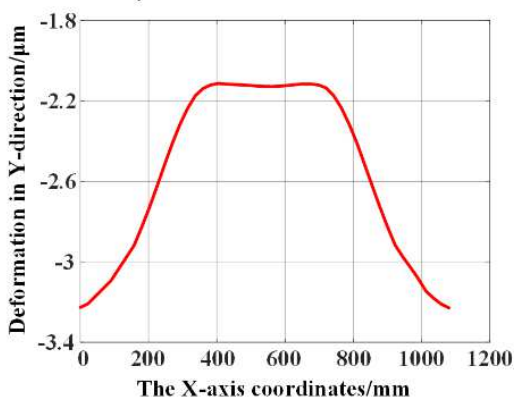

(j) Deflection curve of $\# 5$ beam obtained by ANSYS simulation

Fig. 6 The beam deformation curves obtained by two analysis methods 


\subsection{Optimization of support position}

It can be seen from Fig. 6 that \#2 beam and \#4 beam can reflect the maximum deformation of the joint surface of the bed and the column. At the same time, $\# 4$ beam can also reflect the deformation of the assembly joint surface of the guide rail and the bed. Therefore, for the statics model of the bed, the position of the corresponding three-point supporting foot is the best when the deformation of \#4 beam is the smallest.

We have obtained the simultaneous equations of the deflection curves of \#4 beam. Then taking the maximum deformation difference of $\# 4$ beam as the optimization goal, and the foot position parameters $K_{l}, K_{2}, K_{3}$ as variables, the optimal set of foot position parameters can be obtained as $K_{l}=796 \mathrm{~mm}$, $K_{2}=690 \mathrm{~mm}, K_{3}=820 \mathrm{~mm}$ by the linear programming.

\section{Experimental verification of simulation results of bed surface deformation}

The goal of this experiment is to obtain the Y-direction deformation on the surface of the T-shaped bed under the condition of three-point support only due to gravity.

\subsection{Experimental equipment}

(1) A simple T-shaped bed: This experiment uses a simple T-shaped bed model, as shown in Fig. 7. The bed is a monolithic casting structure with a Tic-shaped rib structure inside, as shown in Fig. 2. The main size parameters of this simple T-shaped bed are shown in Table 3.

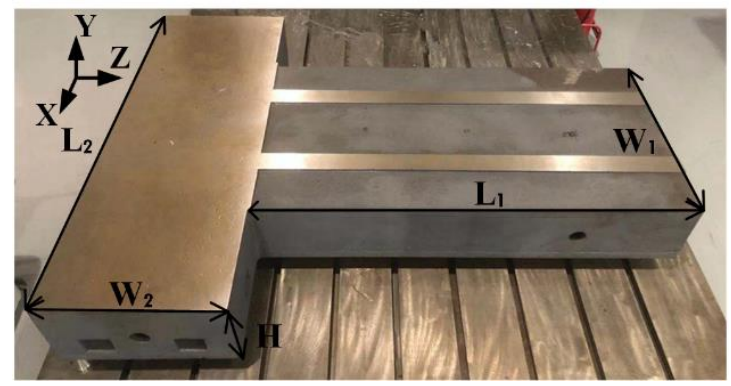

Fig. 7 The simple T-shaped bed

Table 3 Main size parameters of the simple T-shaped bed

\begin{tabular}{cccc}
\hline Parameter & Value & Parameter & Value \\
\hline The width of the front bed $\mathrm{W}_{1}(\mathrm{~mm})$ & 840 & The width of the front bed $\mathrm{W}_{2}(\mathrm{~mm})$ & 600 \\
The length of the front bed $\mathrm{L}_{1}(\mathrm{~mm})$ & 1650 & The length of the front bed $\mathrm{L}_{2}(\mathrm{~mm})$ & 1665 \\
Beam thickness $\mathrm{b}(\mathrm{mm})$ & 40 & Bed height $\mathrm{H}(\mathrm{mm})$ & 310 \\
\hline
\end{tabular}

(2) Collapex Digital Autocollimator: This experiment uses a digital autocollimator for highprecision angle measurement. The instrument has a high-precision area array detector and uses the principle of self-collimation measurement. The horizontal deformation and vertical deformation can be measured by this instrument at the same time.

\subsection{Experimental equipment}

For the upper surface of the simple bed, only the joint surface of the bed and the column and the base surface of the two guide rails are finished. In order to obtain as much as possible the deformation results of the bed surface in the Y-direction, the measurement objects of this experiment are the Xdirection straight line of the back bed and the Z-direction straight line where the left and right guide rails are located, as shown in Fig.8.

Factors such as artificial errors and noise errors during the experiment will inevitably affect the results of the experiment. In order to make the Y-direction deformation of the bed due to gravity large enough under the three-point support to facilitate measurement and comparison, the 3-point support position designed in this experiment is shown in Fig. 8(a).

Due to the machining error of the bed, we also measure a set of deformation experiments of the bed under the 21-point support. The 21-point support position designed in this experiment is shown in Fig. $8(b)$. This measurement result is used to simulate the machining error of the bed. 


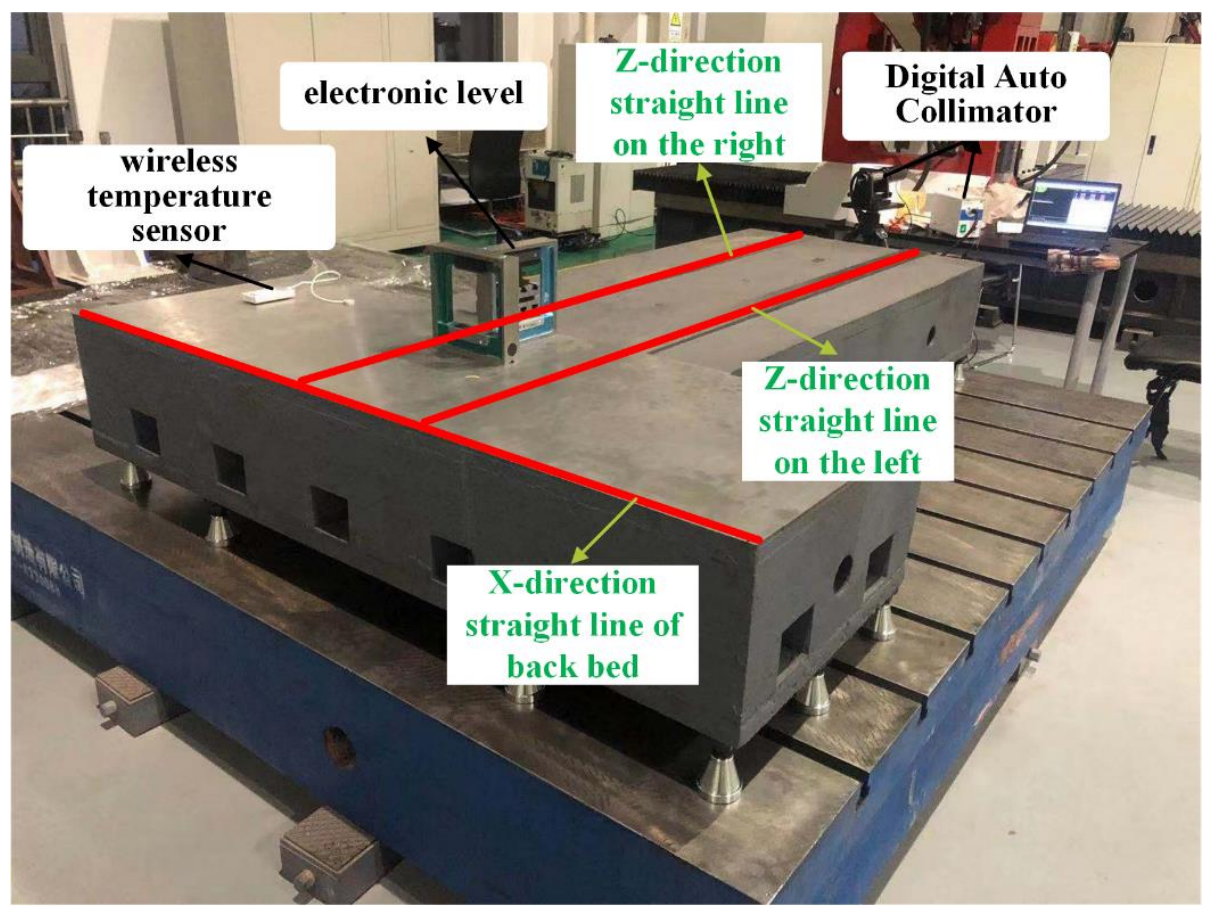

Fig. 8 Confirmatory experiment

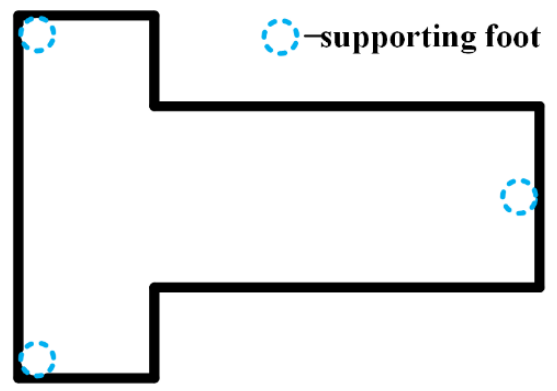

(a) Position distribution of 3-point support

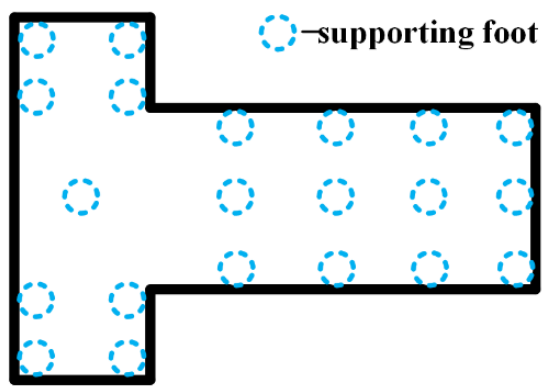

(b) Position distribution of 21-point support

Fig. 9 Position distribution map of supporting foot

Notes in the experiment:

(1) Before the experiment, the bed must be leveled so that the surface of the bed is as perpendicular as possible to the direction of the acceleration of gravity.

(2) The temperature of the experimental measurements should be kept as consistent as possible to reduce the influence of temperature on the measurement results.

\subsection{Experimental results}

The measuring instrument cannot be at an absolute level during the experiment. Therefore, the measured data needs to be processed by the two end-point method to obtain the straightness of the measured straight line. 
The experiments were carried out in an environment of $23 \pm 0.5^{\circ} \mathrm{C}$. Therefore, the environmental temperature has little effect on the deformation of the bed. The measurement results of the digital autocollimator for the deformation in the Y-direction of the three straight lines are shown in Fig.10.

- 3-point support

- 21-point support

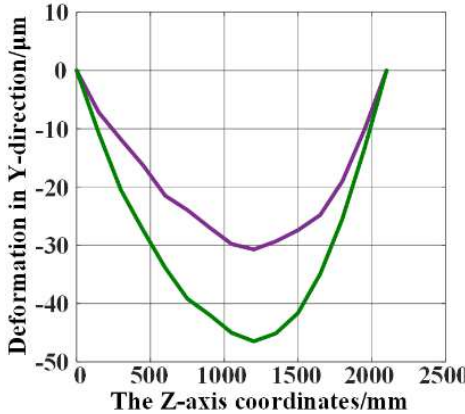

(a) Deformation curve of $Z$ -

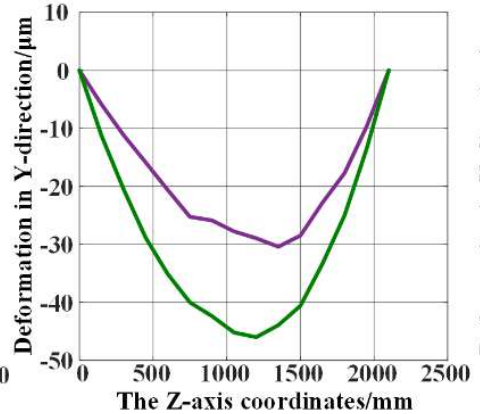

(b) Deformation curve of Z-

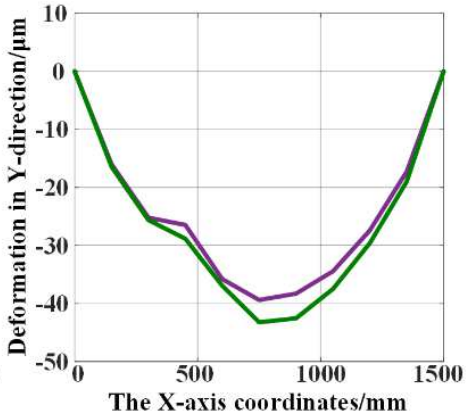

(c) Deformation curve of $\mathrm{X}$ -

direction straight line on the left direction straight line on the right direction straight line of back bed

Fig. 10 Measurement results of digital autocollimator

For the simulation results, the straight line deformation curves in the Z-direction of the left and right guide rails of the bed are consistent. The results of the simulation analysis are shown in Fig. 11 and Fig.12.

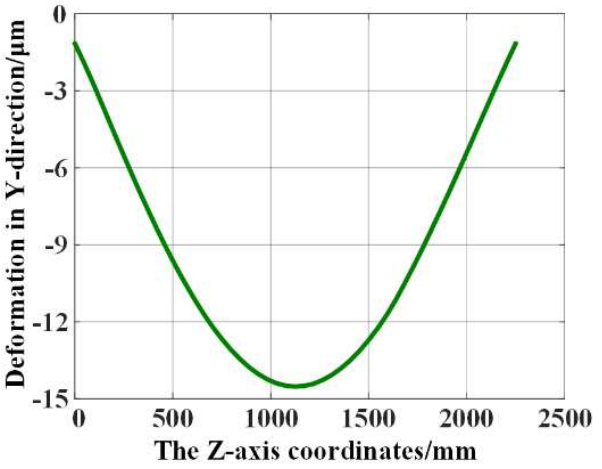

(a) Deformation curve of Z-direction straight line on the left/right

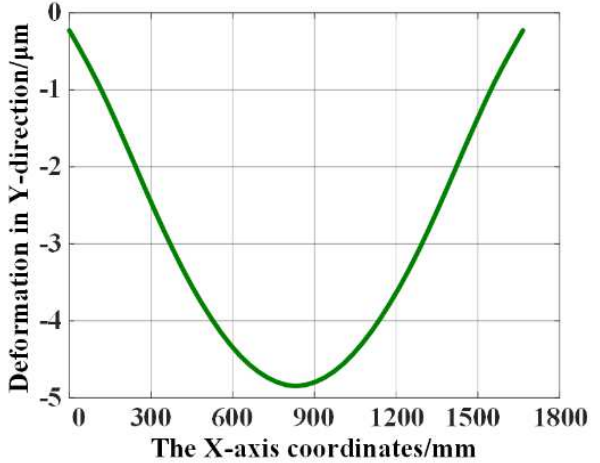

(b) Deformation curve of $\mathrm{X}$ direction straight line of back bed

Fig. 11 Simulation analysis results under 3-point support

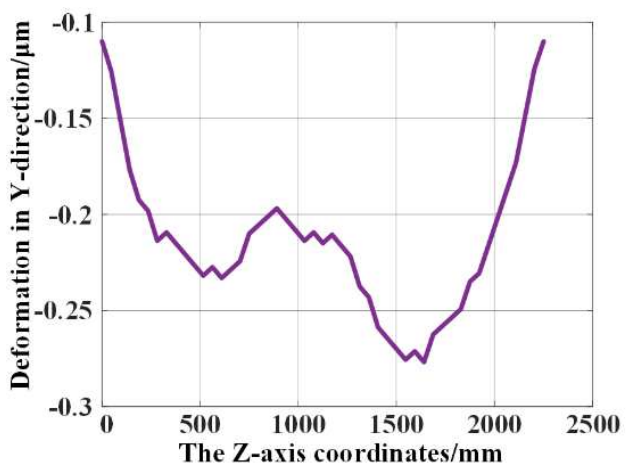

(a) Deformation curve of $\mathbf{Z}$-direction straight line on the left/right

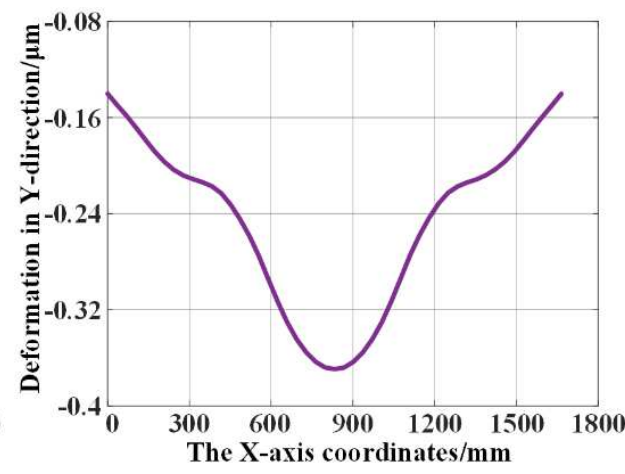

(b) Deformation curve of $\mathrm{X}$ direction straight line of back bed

Fig. 12 Simulation analysis results under 21-point support

It can be seen from Fig. 10 to Fig. 12 that when the bed is supported at 21 points, the simulation analysis result is much smaller than the measurement result of the digital autocollimator. This means that the deformation of the bed under the 21-point support due to gravity is much smaller than its own processing error. Therefore, this part of the measurement result can be approximately regarded as the machining error value of the measured linear position. For the two support methods of the bed, the difference between the measurement results of the autocollimator can used to reflect the deformation of 
the bed only due to gravity.

It can be seen from Fig.10 that due to the influence of gravity, the three straight lines all have a concave change in the Y-direction. The straightness changes of the three straight lines are respectively $15.77 \mu \mathrm{m}, 15.60 \mu \mathrm{m}$ and $3.84 \mu \mathrm{m}$. From the simulation results, the deformation trends of these three straight lines in the Y-direction are also concave, and the straightness changes are respectively $13.21 \mu \mathrm{m}$, $13.20 \mu \mathrm{m}$ and $4.41 \mu \mathrm{m}$. The error between experimental results and simulation results is within $20 \%$, which can also prove that the simulation results of the surface deformation of the bed with ANSYS are reliable. This experiment can also show that it is reasonable to simplify the bed to a grillage-beam model for analyzing the static deformation trend of the bed.

\section{Multi-objective optimization of three-point support position based on ISIGHT}

\subsection{Multi-objective optimization}

Multi-objective optimization problem refers to an optimization problem with two or more objective functions. Usually, the sub-objective functions are contradictory, which means that the pros and cons of one sub-objective are often restricted by other sub-objective functions. ${ }^{19}$ Therefore the solution of the multi-objective optimization problem does not have uniqueness. We can only take into account the requirements of each sub-objective as much as possible within the design range, and obtain a series of acceptable solutions to form a relatively uniformly distributed effective solution set, called the Pareto solution set.

\subsubsection{Selection of design variables}

The CAD model of the bed of the M800H horizontal machining center is shown in Fig.2. The bed is supported by three horns, and the supporting positions are distributed in an isosceles triangle. The contact surface between the bed and the horn is simplified into three rectangular areas with a length of $400 \mathrm{~mm}$ and a width of $200 \mathrm{~mm}$. The main structural dimensions of the bed are shown in Table 2. When the size of the bed structure is determined, the three-point support position can be uniquely determined by the three position parameters $K_{1}, K_{2}$ and $K_{3}$. Therefore, $K_{1}, K_{2}$ and $K_{3}$ are selected as the design variables of the optimization problem. The initial values of the design variables and the design spaces are shown in Table 4.

Table 4 The initial values of the design variables and the design space

\begin{tabular}{ccc}
\hline The design variables $(\mathrm{mm})$ & The initial values $(\mathrm{mm})$ & The design spaces $(\mathrm{mm})$ \\
\hline$K_{1}$ & 560 & {$[200,1035]$} \\
$K_{2}$ & 540 & {$[100,1257]$} \\
$K_{3}$ & 680 & {$[100,2435]$} \\
\hline
\end{tabular}

\subsubsection{Determination of the objective function}

The bed is an important supporting part of the machine tool. Its main function is to support other parts of the machine tool, such as guide rails, sliding seats, columns and so on. It also provides operating orbits for the mechanical movement of some components, such as the Z-direction movement of the sliding seat and the worktable. In order to ensure the machining accuracy of the machine tool, the bed must have a high static rigidity. The bed is only subject to its own gravity during assembly. Therefore, the T-shaped bed must meet the following design requirements:

(1) The static rigidity of the bed is large enough, which means that the maximum deformation of the bed $d_{\max }$ under the action of gravity is as small as possible.

(2) The deformation difference of the guide rail $d_{1}$ is as small as possible, which means that the deformation of the guide rail is as uniform as possible under the action of gravity. The maximum deformation difference is specified to be no more than $3 \mu \mathrm{m}$.

(3) The deformation difference of the back bed $d_{2}$ is as small as possible, which means that the deformation of the back bed is as uniform as possible under the action of gravity. The maximum deformation difference is specified to be no more than $3 \mu \mathrm{m}$.

(4) The first-order natural frequency of the bed after optimization $f_{1}$ cannot be lower than the first-order natural frequency before optimization $f_{0}$.

In summary, the mathematical model of the multi-objective optimization problem is: 


$$
\begin{array}{ll} 
& \text { Min } f(x)=\left[d_{1}, d_{2}, d_{\text {max }}\right] \\
\text { s.t. } & 200 \leq K_{1} \leq 1035 \\
& 100 \leq K_{2} \leq 1257 \\
& 100 \leq K_{3} \leq 2435 \\
& f_{1} \geq f_{0}
\end{array}
$$

\subsection{Optimized process based on ISIGHT}

ISIGHT software is a multi-disciplinary co-simulation software launched by French's Dassult. After years of development, it has become the most representative multi-disciplinary co-optimization software. ISIGHT software realizes the automation and digitization of the product design process, and effectively reduces the product development cycle.

For this multi-objective optimization problem, we adopted the second-generation non-dominant ranking genetic algorithm NSGA-II provided by ISIGHT. In the process of solving the Pareto solution, this algorithm does not use a weighted method to process multiple targets into a single target, but uses a direct exploration method to avoid the situation where the Pareto frontier cannot be explored. The process of solving the Pareto solution is:

(1) Select multiple initial design points in the design space to form the initial population $\mathrm{P}_{0}$.

(2) The population $P_{0}$ is subjected to mutation and crossover operations in accordance with the general process of the traditional genetic algorithm to obtain a new population $\mathrm{P}_{1}$, and then the two populations are merged.

(3) Through the methods of "non-inferior ranking" and "crowding distance ranking", the better solutions in $\mathrm{P}_{1}$ are retained to form a new parent population $\mathrm{P}_{2}$, and then the above process is repeated until the convergence condition is met.

In the NSGA-II optimization algorithm, we set the population number to 20 , the genetic generation number to 12 generations, and the cross mutation rate to be 0.9 . The flowchart of ISIGHT-based multiobjective joint optimization is shown in Fig. 13.

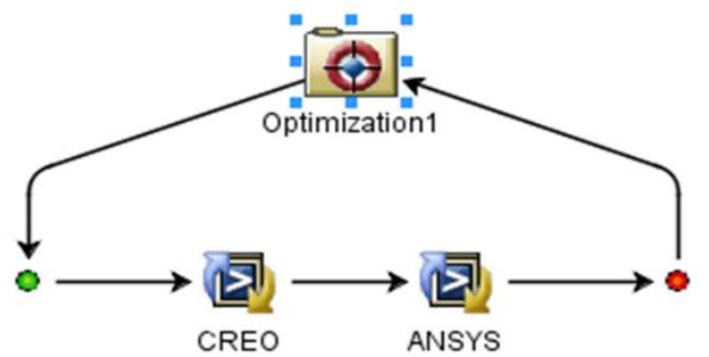

Fig. 13 The flowchart of ISIGHT-based multi-objective joint optimization

\subsection{Optimized result}

After 240 iterations, 12 sets of Pareto solutions can be obtained, which constitute the solution set of the multi-objective optimization problem, as shown in Table 5. It can be seen from the table that the value ranges of the optimal bed support position parameters obtained with the static performance as the

\begin{tabular}{|c|c|c|c|c|c|}
\hline$K_{I}(\mathrm{~mm})$ & $K_{2}(\mathrm{~mm})$ & $K_{3}(\mathrm{~mm})$ & $d_{\max }(\mu \mathrm{m})$ & $d_{1}(\mu \mathrm{m})$ & $d_{2}(\mu \mathrm{m})$ \\
\hline 773 & 651 & 824 & 4.236 & 1.495 & 1.997 \\
\hline 771 & 692 & 755 & 4.211 & 1.485 & 2.265 \\
\hline 782 & 574 & 811 & 4.105 & 1.536 & 2.022 \\
\hline 779 & 708 & 730 & 4.313 & 1.407 & 2.865 \\
\hline 781 & 623 & 811 & 4.063 & 1.555 & 1.695 \\
\hline 778 & 702 & 740 & 4.286 & 1.441 & 2.731 \\
\hline 782 & 623 & 821 & 4.127 & 1.536 & 1.747 \\
\hline 782 & 577 & 831 & 4.237 & 1.485 & 2.173 \\
\hline 778 & 623 & 804 & 4.070 & 1.586 & 1.664 \\
\hline 773 & 630 & 829 & 4.248 & 1.527 & 1.886 \\
\hline 780 & 623 & 799 & 4.065 & 1.582 & 1.685 \\
\hline
\end{tabular}
optimization goal are $771 \mathrm{~mm} \leq K_{1} \leq 808 \mathrm{~mm}, 574 \mathrm{~mm} \leq K_{2} \leq 708 \mathrm{~mm}, 730 \mathrm{~mm} \leq K_{3} \leq 831 \mathrm{~mm}$. In the Section 2 , the optimal support position parameter values $K_{I}=796 \mathrm{~mm}, K_{2}=690 \mathrm{~mm}, K_{3}=820 \mathrm{~mm}$ obtained by the simplified statics model are just within the Pareto solution set interval obtained by the multiobjective optimization. This can also prove the accuracy of the statics model of the bed. 
It can be seen that there are mutual constraints between the three static performance evaluation functions of the bed. Therefore, the designer needs to weigh the various objective functions to select the optimal solution. In this paper, we select the optimal support position parameters obtained in the Section 2 for the T-shaped bed.

\section{Comparison of optimization results}

\subsection{The maximum deformation of the bed}

The bed models before and after optimization are respectively simulated with only gravity. The deformation cloud atlases obtained are shown in Fig.14. It can be seen that the position of the maximum deformation of the bed before optimization is at the junction of the front bed and back bed, and the maximum deformation value is $5.63 \mu \mathrm{m}$. The maximum deformation value of the bed after optimization is $4.10 \mu \mathrm{m}$, which appears at the end of the front bed. The maximum deformation of the bed after optimization is reduced by $27.1 \%$ compared with that before optimization, which significantly improves the static rigidity of the bed.

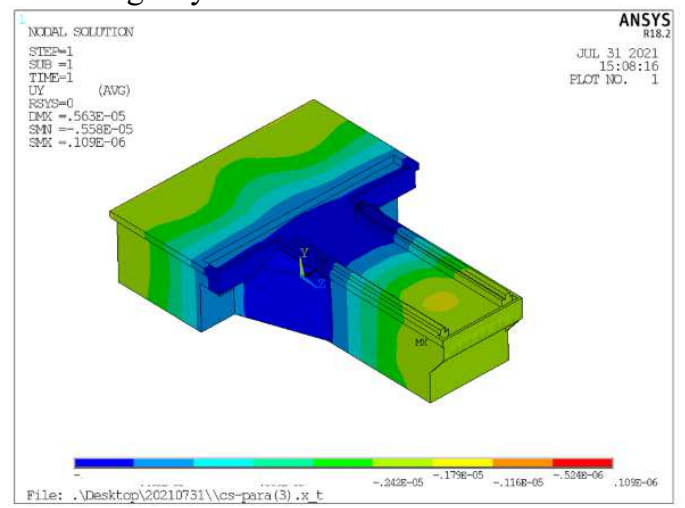

(a) Deformation cloud atlas before optimization

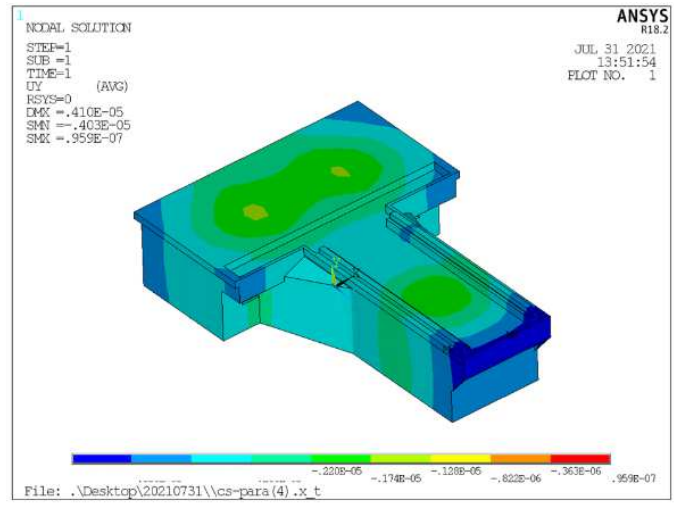

(b) Deformation cloud atlas after optimization

Fig. 14 Deformation cloud atlases of T-shaped bed before and after optimization

\subsection{The deformation of the guide rail}

According to the finite element analysis results of the bed, the comprehensive deformation values of the nodes on the upper surface of the guide rail are extracted. The deformation curves of the guide rail can be obtained through curve interpolation and function fitting in MATLAB, as shown in Fig. 15.

\section{Deformation curves of the guide rail}

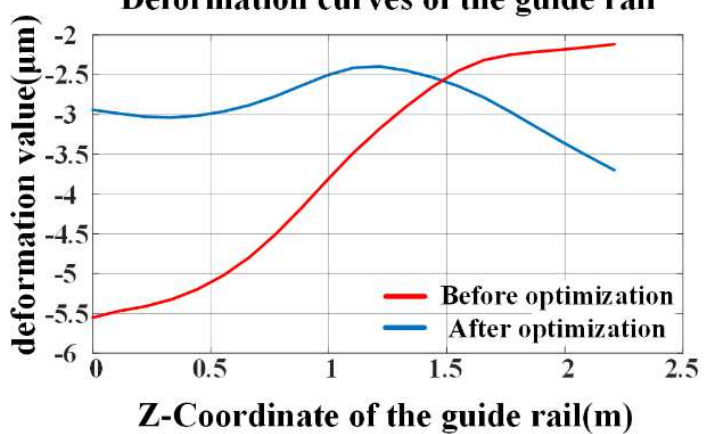

Fig. 15 Deformation curves of guide rail before and after optimization

It can be seen that the maximum deformation value of the guide rail after optimization is $3.70 \mu \mathrm{m}$, which appears at the end of the guide rail. The minimum deformation value is $2.40 \mu \mathrm{m}$, which appears near the support point. The deformation difference of the optimized guide rail surface is $1.30 \mu \mathrm{m}$, which meets the design requirements in Section 4. The deformation of the guide rail after optimization is more uniform line significantly, as shown in Fig. 15.

\subsection{The deformation of the back bed}

According to the finite element analysis results of the bed, the deformation value of the surface of the back bed are extracted to drawn into a deformation map, as shown in Fig.16. It can be seen that the maximum deformation value of the back bed after optimization is $4.54 \mu \mathrm{m}$, which appears at the corner 
of the back bed. The minimum deformation value is $1.80 \mu \mathrm{m}$, which appears near the support point. The deformation difference of the back bed after optimization is $1.30 \mu \mathrm{m}$, which meets the design requirements in Section 4.

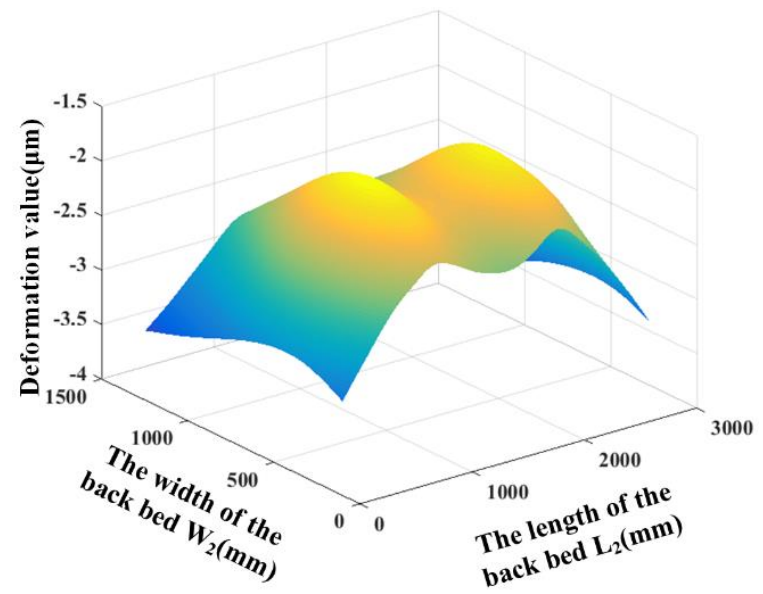

Fig. 16 Deformation map of the back bed surface after optimization

\subsection{Dynamic characteristics of the bed}

We carried out modal analysis on the beds before and after optimization. The simulation results of the first four natural frequencies and mode shapes are shown in Table 6 . The first four-order mode cloud atlases of the T-shaped bed after optimization are shown in Fig. 17.

Table 6 Comparison of the Dynamic characteristics of the beds before and after optimization

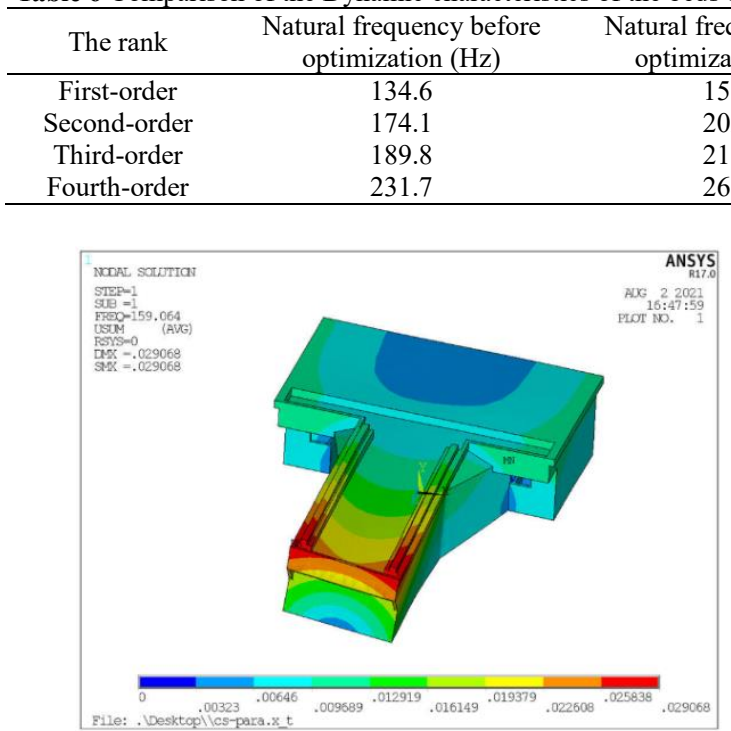

(a) The first mode shape

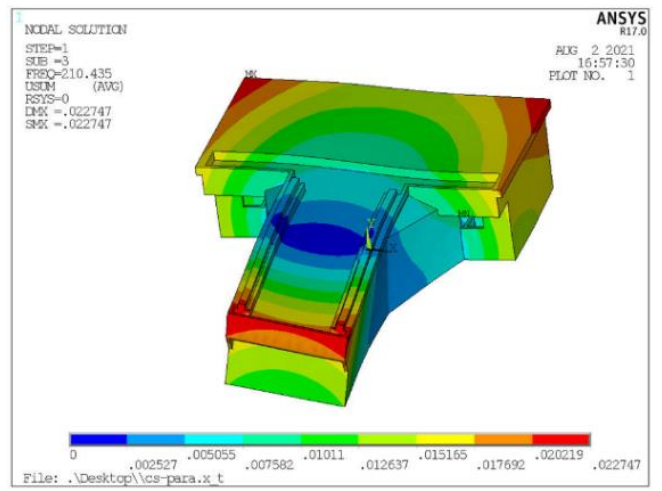

(c) The third mode shape

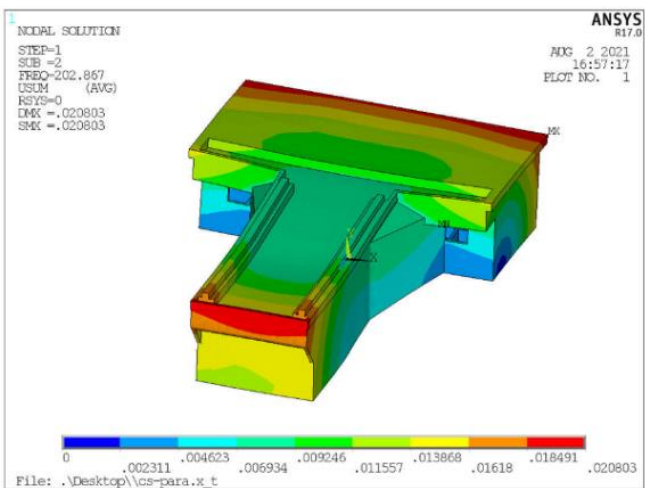

(b) The second mode shape

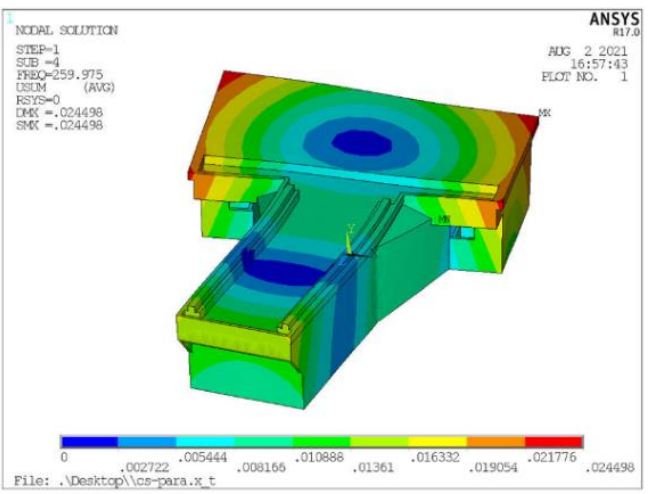

(d) The fourth mode shape

Fig. 17 The first four-order mode cloud atlases of the T-shaped bed after optimization 
It can be seen that the natural frequencies of each order of the optimized bed meet the constraint requirements, and the first-order natural frequency of the bed is increased by $18.2 \%$.

\subsection{The static characteristics of the whole machine}

The CAD model of the M800H precision horizontal machining center is shown in Fig.1. The main components of this precision horizontal machining center include bed, column, slide, spindle box, spindle, workbench, etc. The whole machine models before and after optimization are respectively simulated with gravity only. The deformation cloud atlases obtained are shown in Fig.18. It can be seen that before the support position is optimized, the maximum deformation of the spindle end is $68.7 \mu \mathrm{m}$, and the maximum deformation of the workbench end is $15.0 \mu \mathrm{m}$. When the support position is optimized, the maximum deformation of the spindle end of the machine tool is $33.8 \mu \mathrm{m}$, and the maximum deformation of the workbench end of the machine tool is $7.5 \mu \mathrm{m}$, which are reduced by $50.8 \%$ and $50.0 \%$ respectively.

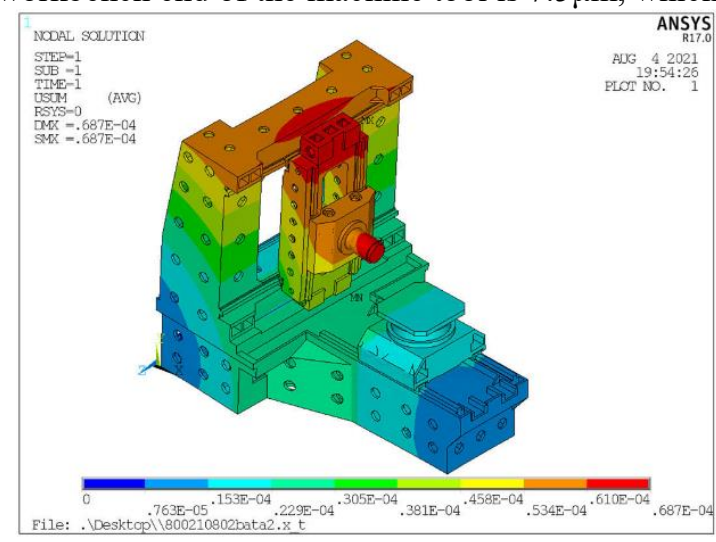

(a) Deformation cloud atlas of the whole machine before optimization

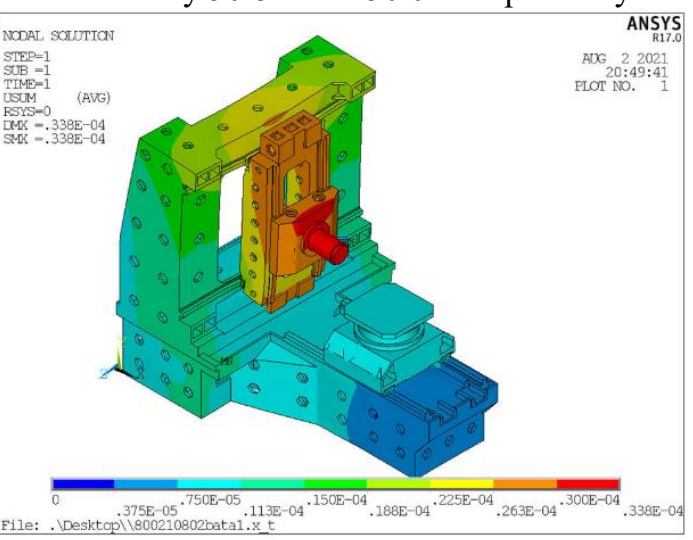

(b) Optimized deformation cloud atlas of the whole machine

Fig. 18 Deformation cloud atlases of the whole machine before and after optimization

\section{Conclusions}

Based on the development trend of the three-point support of machine tools, this paper presents an optimized design method of three-point support for T-shape bed of precision horizontal machining center. The following conclusions can be drawn.

1. This paper establishes the static model of the T-shaped bed by simplifying the bed with a Ticshaped rib structure inside to a grillage-beam model. The static model can characterize the static deformation trend of the surface of the bed and obtain the optimal three-point support position layout. In the confirmatory experiment of the simulation results of surface deformation on the bed, the error between the simulation results and the experimental results is within $20 \%$, which confirms the authenticity of the simulation results. The static deformation trend of the bed obtained by the statics model is consistent with the simulation results, which verifies the rationality of the statics model. This static model provides a preliminary theoretical basis for the layout design of the three-point support of the bed.

2. This paper obtains the Pareto solution set of the multi-objective optimization model for threepoint support position based on ISIGHT, which can verify the accuracy of the bed statics model. The optimization objectives of this multi-objective optimization model are the static rigidity of the bed, the deformation difference of the guide rail and the deformation difference of the back bed. According to the design requirements and the actual production of the machine tool, the designer can select the weight of each optimization goal to obtain a three-point support position layout that is more in line with actual needs.

3. We takes the $\mathrm{M} 800 \mathrm{H}$ precision horizontal machining center as an example to compare the simulation results before and after the optimization of the support position. When the support position is optimized, the maximum deformation of the bed is reduced by $27.1 \%$, the maximum deformation of the spindle end of the machine tool is reduced by $50.8 \%$, and the maximum deformation of the workbench end of the machine tool is reduced by $50.0 \%$. The result of the comparison proves the effectiveness of the optimization method.

\section{Declarations:}

\section{Funding}


The authors gratefully acknowledge the supports of the National Key R\&D Program of China [grant number 2018YFB1701201].

\section{Conflicts of interest/Competing interests}

All authors certify that they have no affiliations with or involvement in any organization or entity with any financial interest or non-financial interest in the subject matter or materials discussed in this manuscript.

\section{Availability of data and material}

All data generated or analyzed during this study are included in this article.

\section{Authors' contributions}

Zixin Lin: Conceptualization, Methodology, Investigation, Writing. Wenjie Tian: Resources, Supervision. Dawei Zhang: Data Curation, Original draft. Weiguo Gao: Validation, Investigation. Lina Wang: Validation, Investigation.

\section{References}

[1] Schellekens P, Rosielle N, et al. Design for precision: current status and trends. CIRP AnnalsManufacturing Technology, 1998, 47(2): 557-586.

[2] TIAN W, GAO W, ZHANG D, et al. A general approach for error modeling of machine tools. International Journal of Machine Tools and Manufacture, 2014, 79: 17-23.

[3] Wang P, Zuo YR, et al. Finite element analysis of static and dynamic characteristics of high-speed horizontal machining center bed. Engineering Solutions for Manufacturing Processes, 2014, 889-890.

[4] Luo WP. Effect of Support Structure on Static and Dynamic Performance of Five-axis CNC Machine. Modular Machine Tool \& Automatic Manufacturing Technique, 2011, 4: 27-30.

[5] Wang QL, Liu YL et al. Analysis of Auxiliary Support Layout in a Machine Tool Bed Based on Finite Element Method. Manufacturing Information, 2013, 08: 184 185.

[6] Szwengier G, Godunski T. Identification of physical parameters in contacts joints models of machines supporting system. Advanced in Engineering Software, 2000, 31(2): 149-155.

[7] Daisuke K, Takahiro I. Stiffness model of machine tool supports using contact stiffness. Precision Engineering, 2013, 37(3): 650-657.

[8] Zhang H, Yu CL et al. Parameters identification method for machine tool support joints. Journal of Tsinghua University. Science and Technology, 2014, 54: 815-821.

[9] Yamanaka M, Konishi M. Optimum rib layout design of machine tools structures using neural networks. Journal of the Japan Society of Precision Engineering, 2007, 73: 1267-1272.

[10] Hinduja S, Nakra BC. An integrated approach to topology, sizing, and shape optimization. Structural and Multidisciplinary Optimization, 2004, 26: 308-317.

[11] Guo CG, Wang PJ, et al. Optimization Design of CNC Machine Tool Spindle Based on Genetic Algorithm. Journal of Northeastern University. Natural Science, 2011, 32(6): 850-853.

[12] Jiang H, Guan YS, et al, Dynamic and Static Multi-objective Optimization of a Vertical Machining Center Based on Response Surface Method. Chinese Journal of Mechanical Engineering, 2011, 47(11): 125-133.

[13] Spath D, Neithardt W, et al. Optimization design with topology and shape optimization. Proceedings of the Institution of Mechanical Engineering, 2002, 216(8): 1187-1191.

[14] Kushnir, E. Optimization of machine tool based on static and dynamic criteria. American Society of Mechanical Engineers, 2002, 451: 201-206.

[15] Spath D, Neithardt W. Optimization design with topology and shape optimization. Proceedings of the Institution of Mechanical Engineering, 2002, 216(8): 1187-1191.

[16] Yun Q, Niu WT et al. Multi-objective optimization of three-dotted supporting of precision machine tool bed structure. Journal of Machine Design, 2015, 32(7): 1-7.

[17] Horibe, T, Asano, N. Large deflection analysis of beams on two-parameter elastic foundation using the boundary integral equation method. JSME International Journal Series A-solid Mechanics and Material Engineering, 2001, 44(2): 231-236.

[18] Hu MY, Wang AW. Approximate analytical solutions to the transient response of unconstrained damped cantilever beams. Journal of Huazhong University of Science and Technology, 2009, 37(11): 108-110.

[19] Qing LY, Xu DG et al. General equation for solving stepped continuous beams. Mechanics in Engineering, 2006, 28(6): 51-53. 
[20] Yang SX, Wang YP. Multi-objective evolutionary algorithm based on Pareto optimality and limited elitist. Computer Engineering and Application, 2007, 43(2): 108-110. 